\title{
ИССЛЕДОВАНИЕ НАПРЯЖЕННО-ДЕФОРМИРОВАННОГО СОСТОЯНИЯ ТРУБНОГО УЗЛА МАРТЕНСИТНОЙ СТАЛИ 15Х5М В ПРОЦЕССЕ ДИФФУЗИОННОЙ СВАРКИ
}

\section{INVESTIGATION OF THE STRESS-STRAIN STATE OF MARTENSITIC STEEL 15CR5MO TUBE SITE IN THE PROCESS OF DIFFUSION WELDING}

Минкевич В.А., Файрушин А.М., Чернятьева Р.Р., Каретников Д.В. ФГБОУ ВПО «Уфимский государственный нефтяной технический университет», г. Уфа, Российская Федерация

\section{V.A. Minkevich, A.M. Fairushin, R.R. Chernyatyeva, D.V. Karetnikov} FSBEI of HPE "Ufa state petroleum technological university",

Ufa, the Russian Federation

e-mail:minkei@mail.ru

Аннотация. Важной задачей, на сегодняшний день, в машиностроительной отрасли является применение надежных и, в тоже время, недорогих материалов при конструировании нефтегазового и нефтеперерабатывающего оборудования. К разряду таких материалов можно отнести жаропрочную сталь мартенситного класса $15 \mathrm{X} 5 \mathrm{M}$, которая при своей невысокой стоимости обладает хорошими прочностными и антикоррозионными свойствами при высоких температурах.

Особенность изготовления трубных узлов и других базовых элементов нефтехимической аппаратуры из стали $15 \mathrm{X} 5 \mathrm{M}$, заключается в необходимости предварительного, сопутствующего 
подогрева и незамедлительного проведения последующей термообработки со строгим соблюдением температурно-временных параметров процесса. Данные мероприятия проводятся с целью снятия остаточных сварочных напряжений и предотвращения образования холодных трещин в процессе сварки и делают процесс изготовления базовых элементов из стали 15Х5М энергозатратным и трудоемким, а в некоторых случаях практически невозможным. Поэтому одним из современных направлений модернизации технологии изготовления сварного нефтегазоперерабатывающего оборудования из мартенситных сталей является уход от традиционных технологий дуговой сварки.

В данной работе приводятся результаты численного моделирования диффузионной сварки трубного узла из мартенситной стали 15 Х5М. Проводится анализ напряженно-деформированного состояния в зоне сварного соединения в условиях проведения процесса диффузионной сварки, на основании которого показана возможность диффузионной сварки трубного узла из мартенситной стали $15 \mathrm{X}$ М, без потери устойчивости заготовки. Проведен расчет температурных полей, полей напряжений и деформаций сварного соединения.

Abstract. The important task of the engineering industry today is the use of reliable and at the same time inexpensive materials in the construction of oil and gas and refining equipment. Heat-resistant steels of martensitic class $15 \mathrm{Cr} 5 \mathrm{Mo}$ belongs to the category of such materials, it has good strength and corrosion resistant feature - at high temperatures and simultaneous with low cost 
The peculiarity fabrication of pipe spools and other basic elements of steel petrochemical equipment of $15 \mathrm{Cr} 5 \mathrm{Mo}$, includes accompanying preheating and the immediate and subsequent heat treatment of the strict observance of temperature and time parameters of the process. These activities are carried out in order to remove residual welding stresses and to prevent cold cracking during welding and make the process of making the steel $15 \mathrm{Cr} 5 \mathrm{Mo}$ the basic elements energy-intensive and time-consuming, and in some cases impossible to make basic elements. Therefore, one of the modern trends of technology modernization welded oil and gas processing equipment from martensite steels is an elimination from the traditional techniques of arc welding.

This paper presents the results of numerical modeling of diffusion welding of a pipe spool made of martensite steel $15 \mathrm{Cr} 5 \mathrm{Mo}$. The analysis of stress and strain state in a welding joint under the conditions of diffusion welding process is carried out, on the basis of which the possibility of diffusion welding of a pipe spool made of martensite steel $15 \mathrm{Cr} 5 \mathrm{Mo}$ is shown without buckling of pipe billets. The calculation of temperature fields, stress and strain fields of a welding joint is made.

Ключевые слова: диффузионная сварка, трубные заготовки, кольцевой стык, напряженно-деформированное состояние, мартенситная сталь.

Key words: diffusion welding, tube billets, ring joint, stress-strain state, martensite steel.

Известно, что при сварке плавлением жаропрочных мартенситных сталей зачастую образуются холодные трещины в сварном шве, околошовной зоне, основном металле, возникают 
напряжения и деформации, которые в ряде случаев могут оказать отрицательное влияние на качество сварной конструкции. Во время изготовления сварных конструкций искажаются проектные формы и размеры изделий, на восстановление которых затрачивается много труда. Во многом это связано с особенностью термодеформационных процессов, проходящих при использовании сварочной дуги. Таким образом, применение сварки плавлением для современных жаропрочных материалов ограничено и требует специальных мероприятий [1]. В связи с этим необходимо рассматривать другие способы сварки, при которых свариваемость сталей значительно улучшается.

Правильное построение технологического процесса сборки и сварки, а также выбор рациональных режимов сварки, как правило, позволяют избежать чрезмерных напряжений и деформаций [2]. На сегодняшний день существует достаточно много различных способов сварки, которые реализуются без расплавления материала и незаменимы для получения соединений современных сплавов, а также обеспечивают точность и высокое качество изделий. Среди таких способов широко распространена диффузионная сварка [3]. Однако, данный вид сварки малоизучен для мартенситных сталей.

Возможность диффузионной сварки трубного узла из мартенситной стали $15 X 5 \mathrm{M}$ определялась путем исследования напряженно-деформированного состояния в процессе сварки из условия отсутствия потери устойчивости сварной заготовки.

Аналитические методы и расчетные формулы определения напряженно-деформированного состояния в сварных соединениях не обладают высокой точностью, позволяют лишь оценить ожидаемые искажения формы и размеров сварного соединения несложной 
сварной конструкции. Они основаны на выражении результата наложения каждого шва в виде сил и перемещений, которые затем можно использовать для расчета формы и размеров конструкции методами сопротивления материалов. Наиболее универсальным и достоверным в настоящее время признаются экспериментальные методы и численное моделирование.

Метод конечных элементов - наиболее современный и точный расчетный метод позволяет определить напряженно-деформированное состояние, как на поверхности, так и в объеме детали. Метод конечных элементов позволяет всесторонне изучить процесс: с точки зрения температурной и механической задачи, учитывать пластические деформации, упрочнение и ползучесть материала. Поэтому в данной работе для определения температурных полей и полей напряжений и деформаций использовался метод конечных элементов, реализованный в программном комплексе ABAQUS [4].

На рисунке 1 показана модель трубного узла, и область нагрева, определяемая геометрическими параметрами нагревательного коврика, который применяется для местной термической обработки и рассчитан на температуру до $1200^{\circ} \mathrm{C}$.Для разработки модели принимали следующие параметры узла: труба из мартенситной стали 15Х5М диаметром 159 мм и толщиной стенки 8мм, участок нагретого металла шириной 300мм, придание трубным заготовкам сжимающего усилия в области стыка 20 МПа и времени выдержки 15 мин.

Подбор режимов сварки производили на основании имеющихся работ [5] в этой области и составили следующие значения: максимальная температура нагрева $1000^{\circ} \mathrm{C}$, давление на свариваемой поверхности 20 МПа, время выдержки при максимальной температуре 15 минут. 


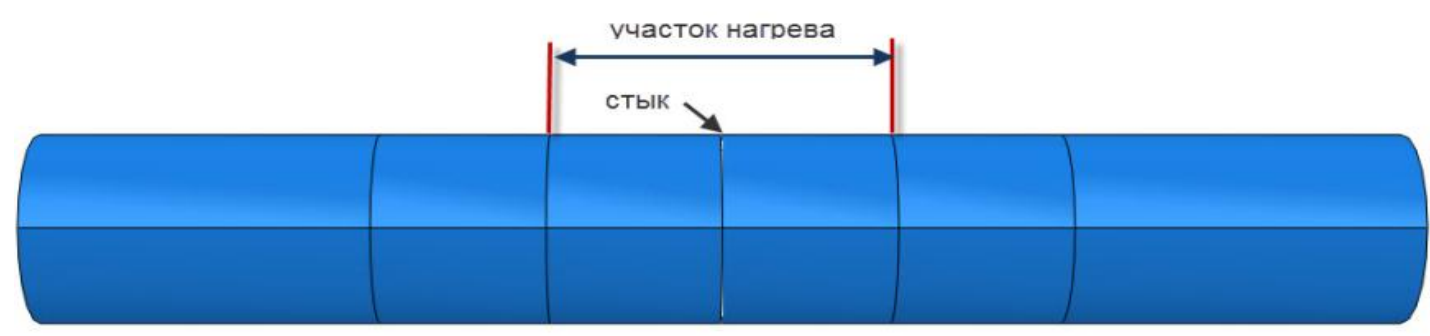

Рисунок 1. Модель трубного узла

Распределение тепловых полей в ходе сварки показано на рисунке 2.

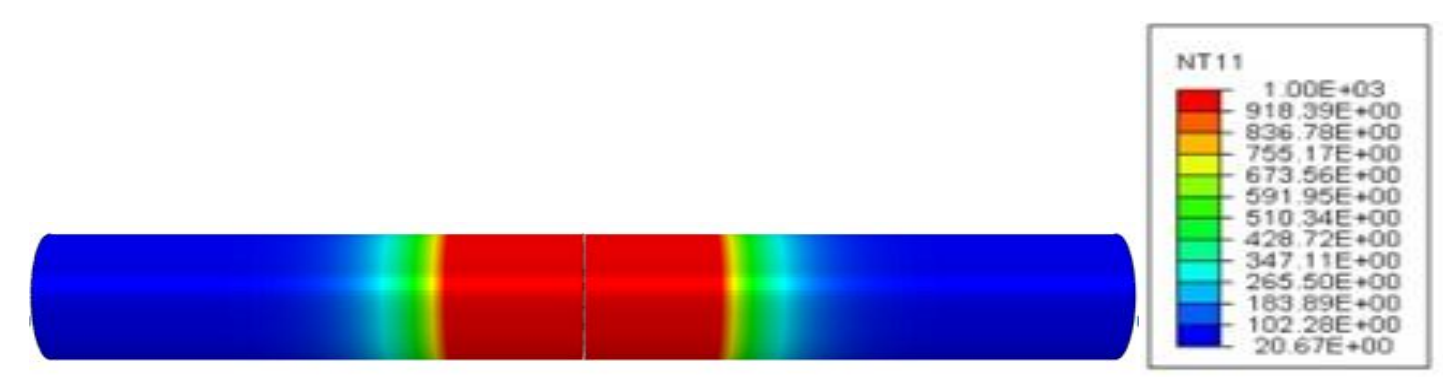

a

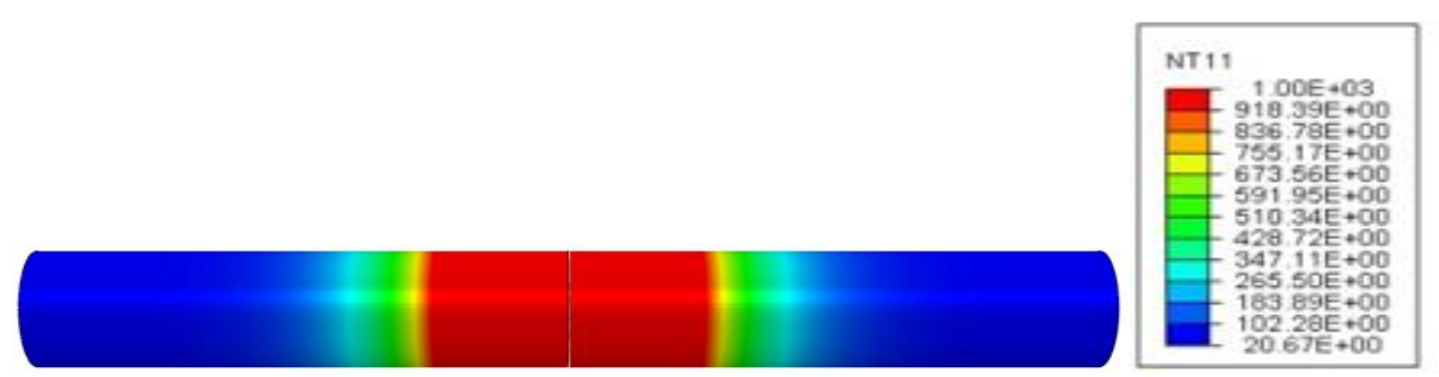

6

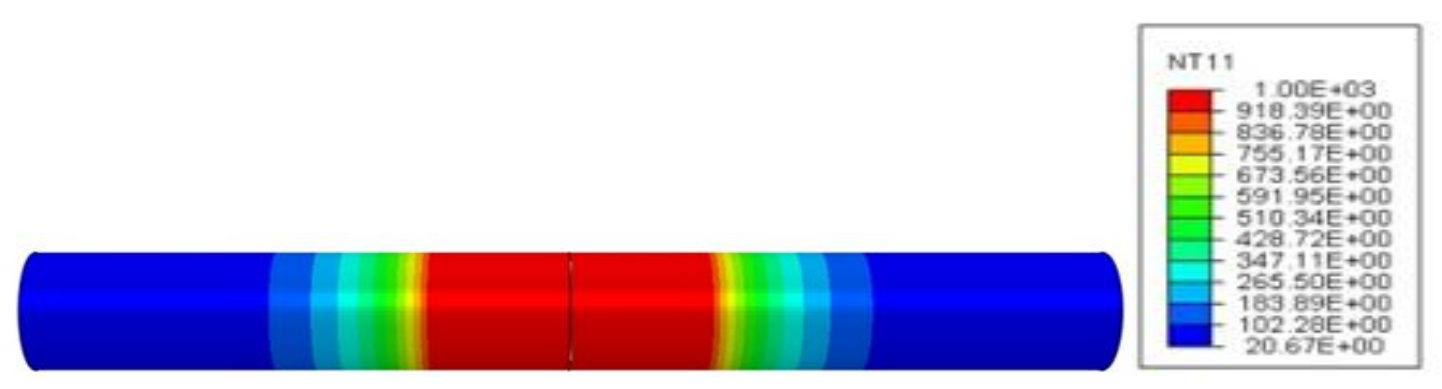

B

Рисунок 2. Распределение тепловых полей в процессе сварки трубных заготовок

a - в начальный момент сварки; б - после 10 минут с начала сварки; в - в момент окончания сварки. 
Для получения качественного сварного соединения необходимо проведение процесса диффузионной сварки в твердой фазе без деформирования свариваемых заготовок. Это возможно в случае, если возникающие в сварном узле в процессе сварки напряжения и деформации не будут превышать предел текучести материала при температурах процесса. Поэтому при подборе режима сварки необходимо учитывать данное условие.

Экспериментально, для стали 15X5М, был построен график и установлена зависимость предела текучести при сжатии от температуры, показанный на рисунке 3. Из графика видно, что при температуре процесса сварки - $1000{ }^{\circ} \mathrm{C}$, предел текучести стали 15Х5М равен 75 МПа.

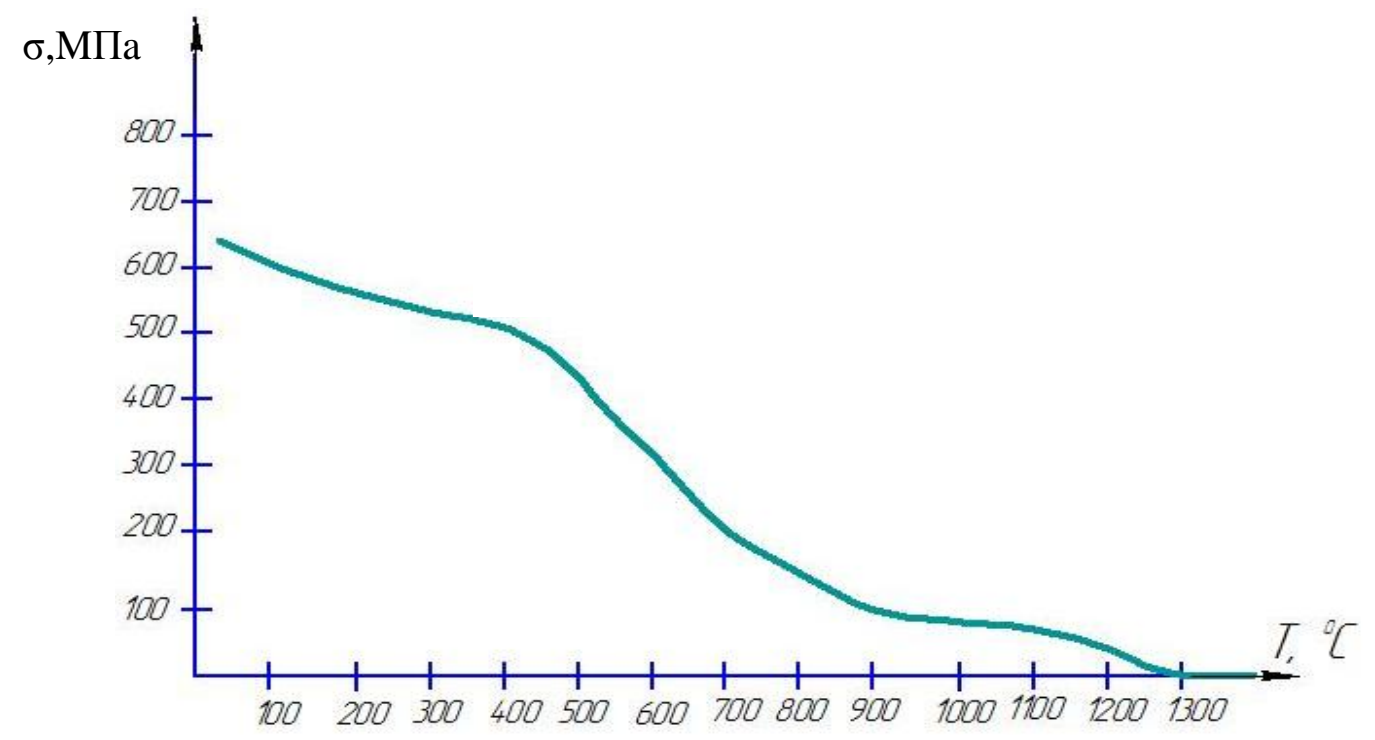

Рисунок 3. График зависимости предела текучести на сжатие стали 15Х5М при различных температурах

Распределение напряжений в свариваемых трубных заготовках в процессе сварки (после 15 минут выдержки при температуре $1000{ }^{\circ} \mathrm{C}$, при действии сжимающего усилия в области стыка 20 МПа) показано на рисунке 4. 

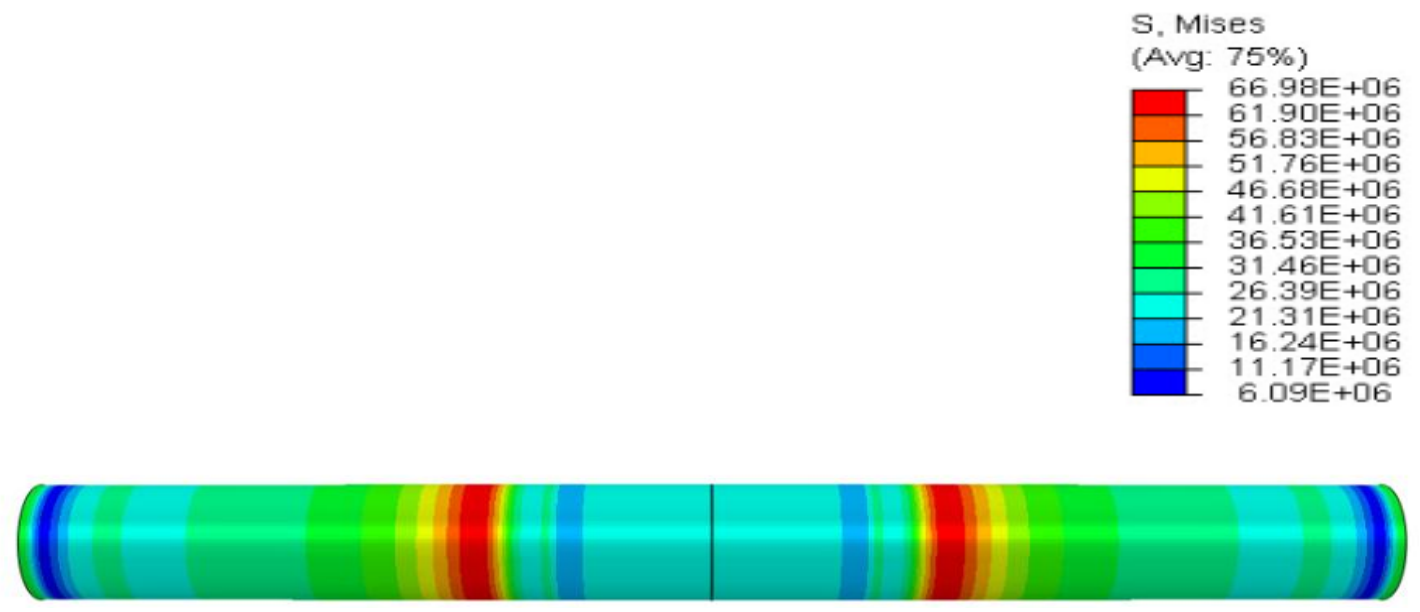

Рисунок 4. Распределение напряжений в свариваемых трубных заготовках в процессе диффузионной сварки, МПа

В результате расчета определили, что максимальное напряжение находятся в зоне перепада температур и имеют значение равное 66,98 МПа. Эта зона является наиболее опасной, но не критической, так как предел текучести при данной температуре для стали $15 \mathrm{X} 5 \mathrm{M}$ составляет 75 МПа. Таким образом, проведенные исследования показали, что при условиях диффузионной сварки данная трубная заготовка не потеряет устойчивость. Этот факт позволяет рассматривать технологию диффузионной сварки для соединения трубных узлов из стали 15 Х5М $[6,7]$.

Результаты, полученные в температурном цикле, использовались в модели структурного анализа в качестве нагрузки, для определения остаточных деформаций, возникающих в результате термодеформационного цикла. Распределение эквивалентных деформаций после сварки трубного узла показано на рисунке 5. 


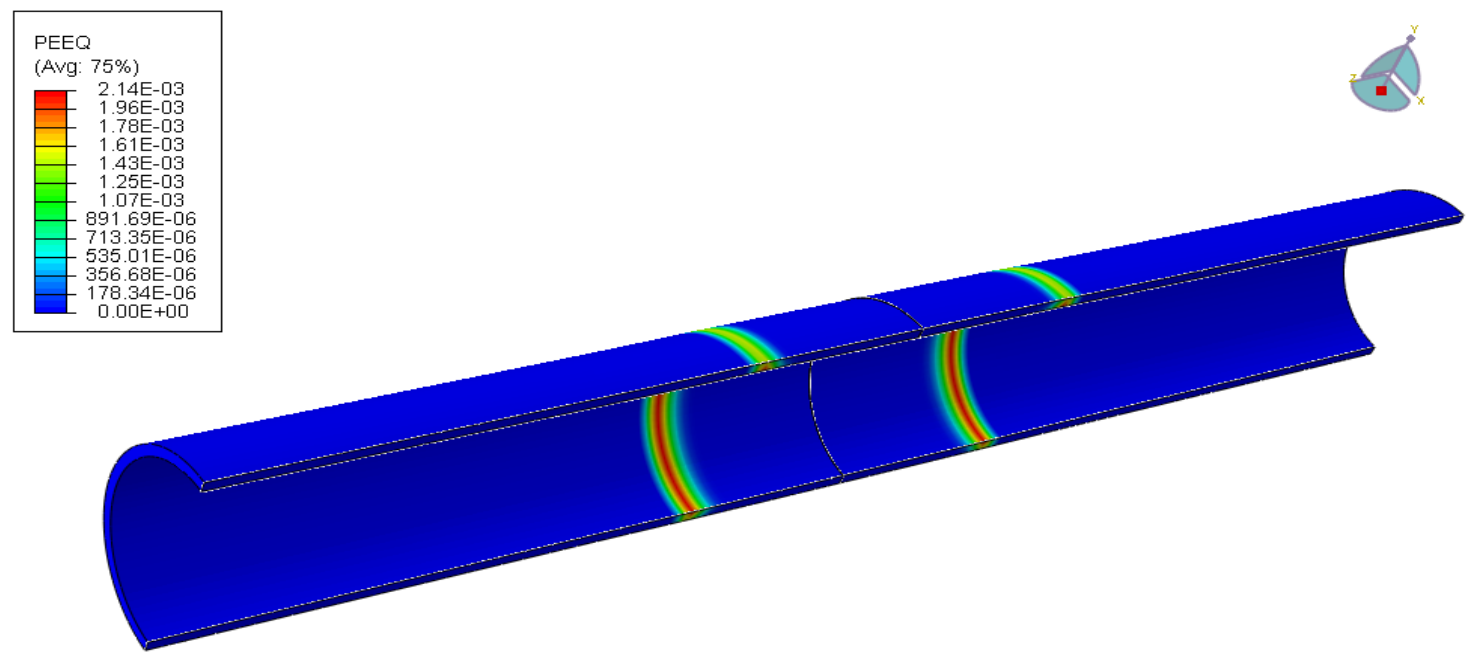

Рисунок 5. Распределение эквивалентных деформаций после приварки трубных заготовок

Данное исследование показывает, что наибольшая концентрация напряжений и деформаций возникает в зоне перепада температур, при этом эквивалентные остаточные деформации достигают 0,2 \%.

\section{Выводы}

1) Проведенные исследования показали, что максимальное напряжение в процессе диффузионной сварки возникает в зоне перепада температур и имеет значение равное 66,98 МПа, которое является приемлемым условием протекания сварочного процесса. Эквивалентные остаточные деформации, возникающие в процессе сварки, находятся также в зоне перепада температур и составляют $0,2 \%$.

2) Результаты данных исследований могут быть использованы при разработке технологии диффузионной сварки базовых элементов нефтегазоперерабатывающего оборудования из жаропрочных, мартенситных сталей. 


\section{Список используемых источников}

1. Акулов А.И.Технология и оборудование сварки плавлением и термической резки. М.: «Машиностроение» 2003. - 560с.

2. БакиевА.В. Технология аппаратостроения. Уфа.: УГНТУ. 1995. - 297 c.

3. Бачин В.А. Теория, технология и оборудование диффузной сварки. -М., 1991. - 352 с

4. Мяченков В.И. Расчеты машиностроительных конструкций методом конечных элементов. М.: «Машиностроение» 1989. - С. 520.

5. Способ сварки давлением разнородных металлов на воздухе / Губарев А.В., Губарев В.В.: пат. 2264898, Рос. Федерация. № 2004113899/02; заявл. $\quad$ 05.05.2004; опубл. 27.11 .2005 . http://www1.fips.ru/fips_servl/fips_servlet. 2 c

6. Сорокин А.В.Влияние остаточных напряжений на размерную стабильность сварных тонкостенных оболочек из малоуглеродистых сталей / Редкол. Журн. «Автоматическая сварка». Киев, 1991. - 10 с. - Деп. в ВИНИТИ 28.08.90, №3531 - В91.

7. Труфяков В.И. О влиянии остаточных напряжений на сопротивление усталости сварных соединений // Автоматическая сварка. 1988. № 2. С.1-4. 


\section{References}

1. Akulov A.I. Tehnologiya i oborudovanie svarki plavleniem i termicheskoj rezki. M.: «Mashinostroenie» 2003 . -560s. [in russian]

2. Bakiev A.V. Tehnologiya apparatostroeniya. UGNTU. Ufa 1995. -297 s. [in russian]

3. Bachin V.A. Teorija, tehnologija i oborudovanie diffuznoj svarki. -M., 1991. - 352 s. [in russian]

4. V.I. Myachenkov. Raschety mashinostroitelnyh konstrukcij metodom konechnyh elementov. M.: Mashinostroenie, 1989. -520 s. [in russian]

5. Sposob svarki davleniem raznorodnyih metallov na vozduhe / Gubarev A.V., Gubarev V.V. pat. 2264898, Ros.Federatsiya. № 2004113899/02; $\quad$ zayavl. $\quad$ 05.05.2004; $\quad$ opubl. 27.11.2005. http://www1.fips.ru/fips_servl/fips_servlet. $2 \mathrm{~s}$

6. A.V. Sorokin. Vliyanie ostatochnyh napryazhenij na razmernuyu stabilnost svarnyh tonkostennyh obolochek iz malouglerodistyh stalej / redkol. zhurn. «avtomaticheskaya svarka». - Kiev, 1991. - 10 s. - dep. v VINITI 28.08.90, №3531 - v.91. [in russian]

7. Trufjakov V.I. O vlijanii ostatochnyh naprjazhenij na soprotivlenie ustalosti svarnyh soedinenij // Avtomaticheskaja svarka. 1988. - № 2. - S.1-4. [in russian] 


\section{Сведения об авторах}

\section{Information about authors}

Минкевич В.А., аспирант кафедры «Технология нефтяного аппаратостроения», ФГБОУ ВПО УГНТУ, г. Уфа, Российская Федерация

V.A. Minkevich, Postgraduate Student, "Petroleum Apparatus Building Technology" department, FSBEI HPE USPTU, Russian Federation

Файрушин А.М., канд. техн. наук, доцент кафедры «Технология нефтяного аппаратостроения», ФГБОУ ВПО УГНТУ, г. Уфа, Российская Федерация

A.M. Fairushin, Candidate of Technical Sciences, Assistant professor, "Petroleum Apparatus Building Technology" department, FSBEI HPE USPTU, Russian Federation

Чернятьева P.Р., канд. физ.-мат. наук, доцент кафедры «Математики», ФГБОУ ВПО УГНТУ, г. Уфа, Российская Федерация

R.R. Chernyatyeva, Candidate of Physical-Mathematical Sciences, Assistant Professor, faculty of "Mathematics", FSBEI HPE USPTU, Russian Federation

Каретников Д.В., канд. техн. наук., преподаватель кафедры «Технология нефтяного аппаратостроения», ФГБОУ ВПО УГНТУ, г. Уфа, Российская Федерация

D.V.Karetnikov, Candidate of Technical Sciences, Lecturer, "Petroleum Apparatus Building Technology" department, FSBEI HPE USPTU, Russian Federation

e-mail:minkei@mai.ru 